\title{
Review the Application of New Technologies in Education on Educational Performance of University Professors Sistan and Baluchestan
}

\author{
Farideh Shahbakhsh ${ }^{1}$, Negar Elhamian ${ }^{2 *}$, Hassah Shahraki Pour ${ }^{3}$ \\ ${ }^{1}$ Department of Educational Sciences, Zahedan Branch, Islamic Aqad University, Zehedan, IRAN \\ ${ }^{2}$ Department Educational Sciences, Kharazmi University, Tehran, IRAN \\ ${ }^{3}$ Department Educational Sciences, Islamic Azad University of Roudehen, Tehran, IRAN
}

\section{*Corresponding Author: Negar Elhamian}

Citation: Shahbakhsh, F., Elhamian, N. and Pour, H. S. (2017). Review the Application of New Technologies in Education on Educational Performance of University Professors Sistan and Baluchestan. Dutch Journal of Finance and Management, 1(2), 47. https://doi.org/10.29333/djfm/5823

Published: October 5, 2017

\begin{abstract}
This study aims to study the impact of the application of new technologies in education on educational performance in Sistan and Baluchestan were university professors. This research is descriptive survey population consisted of all faculty members in Sistan and Baluchestan, that number was 506, according to Morgan 217 subjects was determined. For simple we have used random sampling. The instrument was a questionnaire containing 30 questions which its validity by experts and teachers and tutors have been approved and reliability Cronbach's alpha coefficient was calculated to 0.913. To analyze the data, descriptive statistics including frequency tables, mean, standard deviation and statistics and single-sample ttest was used to analyze research questions using SPSS software was performed on the data. Test results showed that the application of new technologies on the performance of educational training professors was effective. As well as training was effective on how to teach the application of innovative technologies, the number of hours of teaching, consulting and training services and quality of university professors.
\end{abstract}

Keywords: academic performance, learning technologies, University of Sistan and Baluchestan

\section{INTRODUCTION}

Higher education considers as a driving force for sustainable development and move towards the knowledge society, a strategic role. In addition, the mentioned countries in the region and international competitive advantage have played a decisive role. In this regard, in the first decade of the third millennium, the university is expected to consider these aspects, social responsibility is more and more attention. To this end, universities and higher education institutions should spearhead the analysis of the realities of society and offers solutions were Transaction. Therefore, during the past two decades in most countries of the world more harmonious higher education programs with the needs of development and improve the quality of higher education makes special sensitivity. Growing need to evaluate the quality of universities and other higher education institutions was felt in most countries of the world (Bazargan, 2007).

One of the main components of quality in higher education 1, the quality of teaching - learning. The quality of this component depends on the quality of teaching and quality of learning. Learning psychology to cognitive and behavioral development perspectives them a theoretical basis for understanding the teacher to select appropriate teaching strategies and achieve the desired level of learning provides learning. On the other hand, teachers' 
awareness of the quality of teaching was able to improve their performance during training methods and procedures and increase the quality of their teaching (Zulfikar, 1996).

Contrary to common perception of educational technology in our society simply means the use of equipment and instructional media in the process of teaching - learning. But also that it comes from a much wider variety of definitions included. Educational technology approach and based on a system approach and the application of the general theory of systems. Note that educational technology utilizes the findings of science to solve all the problems of teaching. It is obvious that the origin of some of the issues in this field are more and more closely, the more uses. Educational technology in each of the branches of such technology includes software components (content) and hardware. Its main purpose is to make learning more effective and sustainable change in the quality of learning and increase the efficiency of the training (Ahadi, 1999). Technology training for teachers to provide learning opportunities for students is more flexible. Tracking the progress of learners and to facilitate their activities, as well as providing an opportunity to create new learning environments is effective (Conole, Oliver and Harvey, 2000).

Improve the quality and performance of universities in the Masters, is capable and competent. One way of ensuring the realization of the mission and goals of university teachers is improving the quality of science. The evaluation of teachers is one of the most important factors in universities and the principal responsibilities for professional development and to maintain and improve them. Technology can be an important factor, perhaps the major, had changed the way teachers. The method of teacher and student, teacher and student had to change. Various aspects of the quality of life of controversial and sometimes challenging academics, the regular and proper use of equipment teaching aids under each topic in schools and universities were neglected. And often the lack of teaching aids was justified by lack of time and lack of equipment (Pazargadi and Khatibian, 2007).

The quality of teaching is the idea that the results of educational research were developed two decades ago. Although the quality of teaching is not described as a special method it requires the use of content and teaching techniques to improve students' learning capacity. The quality of teaching, teaching and learning in the sense of repetition is not knowledge transfer, but the quality of teaching is creating conditions that students and teachers are active. And substantially contribute to the development of knowledge and were grown as human beings. The process thus developed to meet the spiritual, emotional, social, and spiritual and so were the students (Lovat and Toomey, 2007). Considering that one is the missions of university training. To know the dimensions and factors affecting educational performance of academics and offering ways to improve the quality of education through the use of innovative technologies considered. So the scientific recommendations from the results of senior managers, teachers and professors in order to implement it were used to promote thought and quality education (Name and Safari, 2011).

\section{Research Questions}

\section{The main question}

1. To what extent the application of new technologies in the educational performance of university teachers training is effective?

Questions subsidiary

1. To what extent is the application of modern technology education is an effective way of teaching professors?

2. To what extent is the application of new technologies on the number of hours of teaching faculty training is effective?

3. To what extent is the application of new technologies to provide advice and service training of university teachers effective?

4. To what extent is the application of new technologies on the quality of education, faculty training is effective?

\section{METHODOLOGY}

Using statistical methods, data analysis is done. This is when the raw data was collected for comparison and analysis of research hypotheses, done. In fact, we analyze the data, followed by the sample to obtain results about the good of our society, we are all. The principle of using descriptive statistics was used to analyze the data. After collecting the data, they will be limited to the data in order to achieve the desired standards. In order to gather information current state of Sistan and Baluchestan University professors have been teaching new technologies. Methods this study was descriptive. The population consisted of all faculty members in Sistan and Baluchestan, that number is 506. In order to determine the method of determining the sample size and sample size krejcie Morgan (1976) was used. Due to the size of the population sample size (as Morgan) for this study was 217.

Likert-type attitude questionnaire on each of the 5 range of options "very high, high, medium, low and very low", respectively. The questionnaire contains 30 questions that after the distribution of the sample was analyzed their experience and expertise. To calculate the validity of the sample questionnaire distributed 30 copies of SPSS statistical analysis software reliability, which obtained Cronbach's alpha was equal to 0.913 Given that a 
Dutch Journal of Finance and Management, 1(2), 47

Table 1. Statistical indicators related to the study variables in study

\begin{tabular}{|c|c|c|c|c|c|c|}
\hline \multirow{2}{*}{ Variable } & \multicolumn{3}{|c|}{ Distribution trend indicators } & \multicolumn{3}{|c|}{ Measures of central tendency } \\
\hline & Standard deviation & Variance & Variation range & Average & Middle & View \\
\hline Teaching methods & 0.77 & 0.599 & 3.57 & 3.3 & 3.18 & 3.71 \\
\hline The number of teaching hours & 0.77 & 0.6 & 4.25 & 3.19 & 3.12 & 3.25 \\
\hline Consulting Research Services & 0.94 & 0.88 & 4 & 3.24 & 3.33 & 3.67 \\
\hline Education Quality & 0.78 & 0.61 & 4.38 & 3.32 & 3.37 & 3.5 \\
\hline Educational practice & 0.63 & 0.402 & 3.07 & 3.26 & 3.23 & 3.57 \\
\hline
\end{tabular}

Table 2. Descriptive statistics of educational performance

\begin{tabular}{ccccc}
\hline Variable & Number & Average & The standard deviation & The mean standard error \\
\hline Educational practice & 217 & 3.26 & 0.63 & 0.043 \\
\hline
\end{tabular}

Table 3. The results of the one-sample t-test

\begin{tabular}{cccccc}
\hline Variable & \multicolumn{4}{c}{ The test $=\mathbf{3}$} \\
\hline & T-statistics & Degrees of freedom & $\begin{array}{c}\text { A significant amount } \\
\text { of (bilateral) }\end{array}$ & $\begin{array}{c}\text { Mean } \\
\text { difference }\end{array}$ & Confidence interval 95\% \\
\cline { 4 - 7 } & & 216 & 0.00 & 0.26 & 0.34 \\
\hline Educational practice & 6.058 & & &
\end{tabular}

Table 4. Descriptive statistics teaching methods

\begin{tabular}{ccccc}
\hline Variable & Number & Average & The standard deviation & The mean standard error \\
\hline Teaching methods & 217 & 3.3 & 0.77 & 0.052 \\
\hline
\end{tabular}

Table 5. Single-sample t test results

\begin{tabular}{|c|c|c|c|c|c|c|}
\hline \multirow[t]{3}{*}{ Variable } & \multicolumn{6}{|c|}{ The test $=3$} \\
\hline & \multicolumn{2}{|c|}{ Confidence interval 95\% } & \multirow{2}{*}{$\begin{array}{c}\text { Mean } \\
\text { difference }\end{array}$} & \multirow{2}{*}{$\begin{array}{c}\text { A significant amount of } \\
\text { (bilateral) }\end{array}$} & \multirow{2}{*}{$\begin{array}{l}\text { Degrees of } \\
\text { freedom }\end{array}$} & \multirow{2}{*}{ T-statistics } \\
\hline & Upper bound & Lower bound & & & & \\
\hline Teaching methods & 0.405 & 0.19 & 0.301 & 0.00 & 216 & 5.73 \\
\hline
\end{tabular}

considerable amount was achieved alpha, so this questionnaire can be run and trusts. In the present study to analyze the data, descriptive and inferential statistical methods were used in the descriptive statistics of indexes such as mean, median, mode, frequency tables and charts and indices of dispersion, such as variance and standard deviation were used and the single-sample t-test was used inferential statistics.

\section{RESULTS}

Table 1 provides general information statistical variables, including measures of central tendency, measures of dispersion tendency of the show.

\section{Data Analysis}

The main question: to what extent the application of new technologies in the educational performance of university teachers training is effective? The effect of the application of innovative technologies for training on educational performance of university teachers using single-sample t mean training performance with the average value (i.e., 3) were compared. The results are shown in Tables 2 and 3.

As can be seen in Table 4 the significant amount of bilateral $t$ test was equal to zero. But the one-sided test. So to get a significant amount of one-sided because of the positive difference (0.26) to zero divided by two. Therefore, a significant amount of one-way is also zero and is less than 0.05 . Therefore, the application of new technologies in the educational performance of university teachers training was effective.

Sub questions: The first sub-question: to what extent the application of new technologies in education is an effective way of teaching professors?

The effect of the application of innovative technologies for teaching the way professors teach using t-test.

Teaching methods with a sample mean of the average value (i.e., 3) were compared. The results are shown in Tables 4 and 5 .

As shown in Table 5, there was a significant amount of bilateral $t$ test was equal to zero. The test was so onesided, but one way to get a significant amount of the difference is due to the positive (0.301) have zero divided by two. Therefore, a significant amount of the check is equal to zero and less than 0.05 . Therefore, the application of new technologies in the way of teaching faculty training was effective. The second sub-question: to what extent the application of new technologies on the number of hours of teaching faculty training is effective? To evaluate 
Table 6. Hours teaching descriptive statistics

\begin{tabular}{ccccc}
\hline Variable & Number & Average & The standard deviation & The mean standard error \\
\hline The number of teaching hours & 217 & 3.29 & 0.77 & 0.052 \\
\hline
\end{tabular}

Table 7. The results of the one-sample t-test

\begin{tabular}{|c|c|c|c|c|c|c|}
\hline \multirow[t]{2}{*}{ Variable } & \multirow[t]{2}{*}{ T-statistics } & \multirow{2}{*}{$\begin{array}{l}\text { Degrees of } \\
\text { freedom }\end{array}$} & \multirow{2}{*}{$\begin{array}{l}\text { A significant } \\
\text { amount of } \\
\text { (bilateral) }\end{array}$} & \multirow{2}{*}{$\begin{array}{c}\text { Mean } \\
\text { difference }\end{array}$} & \multicolumn{2}{|c|}{$\begin{array}{c}\text { The test }=3 \\
\text { Confidence interval } 95 \%\end{array}$} \\
\hline & & & & & Lower bound & Upper bound \\
\hline $\begin{array}{l}\text { The number of } \\
\text { teaching hours }\end{array}$ & 5.73 & 216 & 0.00 & 0.301 & 0.19 & 0.405 \\
\hline
\end{tabular}

Table 8. Descriptive statistics provide advice and scientific services

\begin{tabular}{ccccc}
\hline Variable & Number & Average & The standard deviation & The mean standard error \\
\hline Provide advice and scientific services & 217 & 3.29 & 0.77 & 0.052 \\
\hline
\end{tabular}

Table 9. One-sample t-test results

\begin{tabular}{|c|c|c|c|c|c|c|}
\hline \multirow{3}{*}{ Variable } & \multirow{3}{*}{ T-statistics } & \multirow{3}{*}{$\begin{array}{c}\text { Degrees of } \\
\text { freedom }\end{array}$} & \multirow{3}{*}{$\begin{array}{l}\text { A significant } \\
\text { amount of } \\
\text { (bilateral) }\end{array}$} & \multirow{3}{*}{ Mean difference } & \multirow{2}{*}{\multicolumn{2}{|c|}{$\begin{array}{c}\text { The test }=3 \\
\text { Confidence interval } 95 \% \\
\end{array}$}} \\
\hline & & & & & & \\
\hline & & & & & Lower bound & Upper bound \\
\hline $\begin{array}{l}\text { Provide advice and } \\
\text { scientific services }\end{array}$ & 5.73 & 216 & 0.00 & 0.301 & 0.19 & 0.405 \\
\hline
\end{tabular}

Table 10. Descriptive statistics of the quality of education

\begin{tabular}{ccccc}
\hline Variable & Number & Average & The standard deviation & The mean standard error \\
\hline Quality of education & 217 & 3.29 & 0.77 & 0.052 \\
\hline
\end{tabular}

Table 11. One-sample t-test results

\begin{tabular}{ccccccc}
\hline Variable & T-statistics & $\begin{array}{c}\text { Degrees of } \\
\text { freedom }\end{array}$ & $\begin{array}{c}\text { A significant } \\
\text { amount of } \\
\text { (bilateral) }\end{array}$ & Mean difference & \multicolumn{2}{c}{ Confidence interval 95\% } \\
\cline { 5 - 7 } $\begin{array}{c}\text { Quality of } \\
\text { education }\end{array}$ & 5.73 & 216 & 0.00 & 0.301 & 0.19 & 0.405 \\
\hline
\end{tabular}

the effect of the application of new technologies on the number of hours of teaching training university professors using single-sample $t$ tests with the mean of the number of teaching hours

By (i.e., 3) compare. The results were as shown in Tables 6 and 7.

As shown in Table 6, there was a significant amount of bilateral t test was equal to zero. But the one-sided test. So to get a significant amount of one-sided because of the positive difference (0.19) to zero divided by two. Therefore, a significant amount of the check is equal to zero and less than 0.05 . Therefore, the application of new technologies on the number of hours of teaching faculty training was effective. Third sub-question: to what extent the application of new technologies to provide advice and service training of university teachers effective? To evaluate the effect of the application of new technologies to provide advice and service training of teachers that use single-sample t test out advice and scientific services with the average value (i.e., 3) compare. The results were as shown in Tables 8 and 9.

As shown in Table 7, there was a significant amount of bilateral t test was equal to zero. But the one-sided test. So to get a significant amount of one-sided because of the positive difference (0.24) to zero divided by two. Therefore, a significant amount of one-sided as zero is less than 0.05 Therefore, the application of new technologies and services to provide advice on scientific training professors was effective. The fourth sub-question: to what extent the application of new technologies on the quality of education professors teaching was effective? To evaluate the effect of the application of new technologies on the quality of education training professors to use single-sample $t$ test out the quality of education with the average value (i.e., 3) were compared. The results are shown in Tables 10 and 11.

As shown in Table 8, there was a significant amount of bilateral t test was equal to zero. But the one-sided test. So to get a significant amount of one-sided because of the positive difference (0.32) to zero divided by two. Therefore, a significant amount of the check is equal to zero and less than 0.05 . Therefore, the application of new technologies on the quality of education professors emphasizes training. 


\section{DISCUSSION AND CONCLUSION}

With regard to the question of the "extent to the application of new technologies in the educational performance of university teachers is effective on teaching? The results showed that the application of new technologies on the performance of the educational training of university teachers, there was a significant positive correlation. In relation to the first sub-question study "to what extent the application of new technologies in education is an effective way of teaching professors?" The results show that the use of modern technology education teachers teach the way of a positive and significant relationship existed. With regard to the second subquestion is "to what extent the application of new technologies on the number of hours of teaching faculty training is effective?" The results show that the application of new technology training and time professors teaching there was a significant positive correlation. And in the framework of the activities of the teachers were given the right to choose. As well as the efforts and contributions of faculty in achieving academic programs, academic centers effective, was in line.

The third sub-study on the question "to what extent the application of new technologies to provide advice and service training of university teachers effective?" The results show that the application of new technologies to provide advice and service training of teachers that there was a significant positive correlation.

The fourth sub-study on the question "to what extent the application of new technologies on the quality of education professors teaching more effective?" The results showed that the application of new technologies on the quality of education professors teaching there was a significant positive correlation. The results of the study results and Ismail Goudarz Vandcheginy and Esmaeeli Seyghaldehi as the effects of technology use data on effectiveness was demonstrated that the level of technology of data (including timeliness, relevance, accuracy, adequacy, real being of speed, accuracy and reduces learning costs) there is a significant difference in efficacy, was in line.

\section{REFERENCES}

Ahadi, D. (1999). Introduction of educational technology, including teaching methods in recent decades. Tehran, Iran.

Bazargan (2007). Continuous evaluation to improve the quality of university: a look at a decade of experience in the higher education system. Proceedings of the Second International Conference on internal evaluation to improve academic quality. Iran Education Measurement and Evaluation Organization. Tehran, Iran.

Conole, G., Oliver, M. and Harvey, J. (2000). An integrated approach to evaluating learning technologies. Proceedings of the IWALT conference. Palmerstone North, 543-556. https://doi.org/10.1109/IWALT.2000.890582

Lovat, T. J. and Toomey, R. (2007). Values education and quality teaching: the double belix effect. Sydney, David Barlow Publishing. pp. 231-244.

Name, K. and Safari, E. (2011). Factors related to the quality of teaching faculty members, a review of previous research. The fifth conference of quality in the university system, Tehran University, College of Technology Colleges. pp. 211-230.

Pazargadi, D. and Khatib, D. (2007). Evaluation of the performance evaluation system of faculty members in the universities of the world. College of Nursing, 16(57), 17-26.

Zulfikar, M. (1996). Analysis of the quality of teaching coaches Humanities University in Tehran. Proceedings of the seminar on bigher education, Tehran, Iran. 